\title{
Barium Isotope Signatures of Barite Diagenesis
}

\author{
JULIA MIDDLETON ${ }^{1}$, ADINA PAYTAN ${ }^{2}$, MAK SAITO ${ }^{1}$ \\ AND TRISTAN J HORNER ${ }^{1}$
}

\author{
${ }^{1}$ Woods Hole Oceanographic Institution \\ ${ }^{2}$ University of California, Santa Cruz \\ Presenting Author: jemiddle@mit.edu
}

Sedimentary barite abundances are widely used to reconstruct variations in past export productivity. The isotopic composition of barium $(\mathrm{Ba})$ in barite is similarly emerging as a tracer of past variations in ocean circulation and carbon export. However, little is known about the Ba-isotopic fidelity of barite during early diagenesis. Likewise, the timescales over which diagenetic processes may affect primary Ba-isotopic trends is poorly constrained. Here we address these issues by presenting Baisotopic results for field samples, which we complement with long-term isotope exchange experiments conducted with natural and synthetic barites. We surveyed Equatorial Pacific Baisotopic compositions in seafloor and water column samples collected during JGOFS and ProteOMZ, respectively. Core-top barites exhibit Ba-isotopic compositions consistent with an upper water column origin. Porewaters exhibit isotopic compositions similar to near-bottom seawater, only slightly heavier than cooccurring barites. Both barites and porewater Ba-isotopic compositions are invariant over the upper $30 \mathrm{~cm}$ of sediment. The minor Ba-isotopic offset between porewaters and barite is unexpected and may indicate additional processes, such as stable mineral recrystallization, or contributions to porewater [Ba] from sources other than barite (e.g., organic matter). To test for additional processes, we assessed rates of the stable mineral recrystallization of barite in the laboratory. We incubated naturally occurring and synthetic barites in solutions of labeled artificial and coastal seawater (filtered to $0.4 \mu \mathrm{m}$ ). Recrystallization is evident under all conditions and for all samples, though the apparent rate is strongly dependent on the initial barite-to-fluid ratio and the type of seawater used for the incubation (artificial or coastal). We discuss our results in the context of using barites to reconstruct the Ba-isotopic evolution of seawater and explore new applications of the incubation method to probe the pathways, rates, and mechanisms of pelagic barite precipitation. 